\title{
ZETA CONVERTER SIMULATION FOR CONTINUOUS CURRENT MODE OPERATION
}

\author{
Sujo Oommen \\ Assistant Professor, School of Electrical \& Electronics Engineering \\ REVA University, Bangalore, India \\ Adithya Ballaji \\ Assistant Professor, School of Electrical \& Electronics Engineering \\ REVA University, Bangalore, India \\ Burri Ankaiah \\ Assistant Professor, School of Electrical \& Electronics Engineering \\ REVA University, Bangalore, India \\ Ananda M H \\ Assistant Professor, School of Electrical \& Electronics Engineering \\ REVA University, Bangalore, India
}

\begin{abstract}
To extract regulated power supply from the inputs of unregulated conditions, the zeta converter topology is the major application in the power electronics current mode operation. Zeta convertor can interfaced for high frequency application with a less switching stress and also it obtains regulated output voltage from the given input voltage which varies below and above output voltage, When compared with buck, boost, buck-boost and cuk converter, it gives non pulsating current with reduced settling time with adaptability. For different duty cycles and constant switching frequencies, the zeta converter with resistive load gives better results for buck and boost application.
\end{abstract}

Keywords: Zeta converter, Duty cycle

Cite this Article: Sujo Oommen, Adithya Ballaji, Burri Ankaiah, Ananda M H, Zeta Converter Simulation for Continuous Current Mode Operation, International Journal of Advanced Research in Engineering and Technology, 10 (1), 2019, pp 243248.

http://iaeme.com/Home/issue/IJARET?Volume=10\&Issue=1

\section{INTRODUCTION}

In the application of power system there are so many limitations especially in basic DC-DC converter. To maintain power quality with good improvement with respect to harmonic reduction, PFC etc and also the output voltage is controlled [1]. A non linear non - inverting 
forth order converter called Zeta converter can be operated as buck - boost - buck with respect to input and operated as boost - buck - boost w.r.t energy output [2].

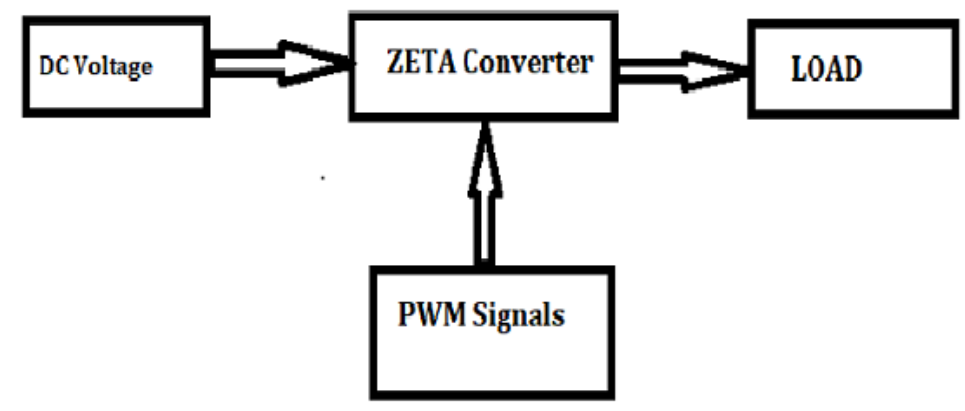

Figure 1 Functional Block Diagram of Zeta Converter.

Any renewable sources as input, the power electronic converter is the basic requirement, like zeta converter which has more advantages than over other converters like boost, buck, buck-boost, sepic and also cuk converter. The zeta converter main advantages are less stress in switching, adaptability, output current is non pulsating. It depends on the duty cycle which can be operate in any mode of operations like boost and buck. If the Photo voltaic system as input, irrespective of alternatives in irradiance, it maintains constant output voltage [2][5].

\section{ZETA CONVERTER}

\subsection{Basic operation of zeta converter}

Zeta converter consists of switch MOSFET, two Capacitors (C1 \& C2), two Inductors (L1 \& L2), only one Diode (D) and the load Resistor (R). Zeta converter circuit is operating under continuous conduction mode $(\mathrm{CCM})$ for switching condition like ON \& OFF.

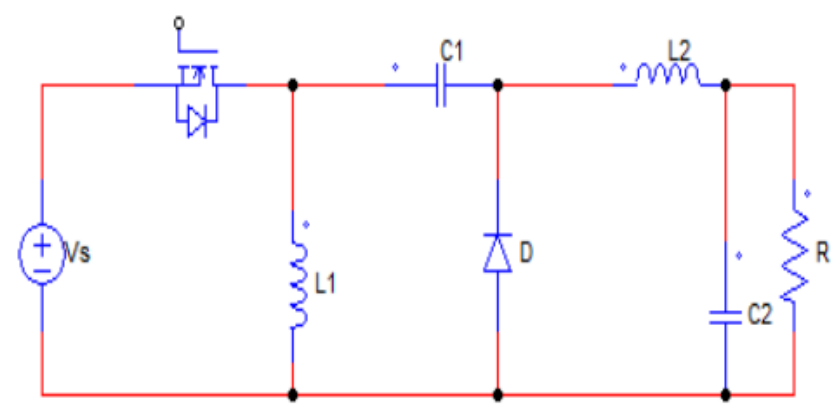

Figure 2 Basic circuit diagram of Zeta Converter

\subsection{Modes of operation with equivalent circuits}

Mode 1:In ON condition the switch, the diode is reverse biased and inductor draws current from the source voltage (Vs), these current through the inductor starts increasing linearly and stored energy in $\mathrm{ON}$ condition mode of operation. The inductor voltage across will be almost equal to the input voltage or source voltage [3]. At the same time capacitor $\mathrm{C} 1$ starts charged to output voltage. When MOSFET is in ON condition, energy from the supply will be stored in the two inductors(L1, L2 )and also C1and L2 provides output currents [2]. 


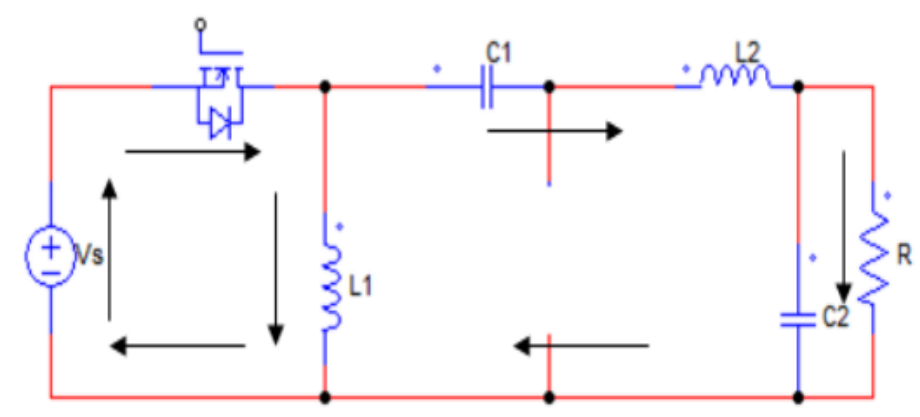

Figure 3 Equivalent circuit diagram during switch is $\mathrm{ON}$

Mode 2: In case 2 or mode 2 the switch is OFF condition, now diode is in forward biased, capacitor will be parallel to L2 inductor and across the inductor output voltage will be available, since $\mathrm{C} 1$ is discharged and $\mathrm{C} 2$ is charged to voltage in output. Whatever energy stored in the inductor (L) will be carry forward to the load resistor. So this kind of mode of operation is discharging conditions. [2][3]

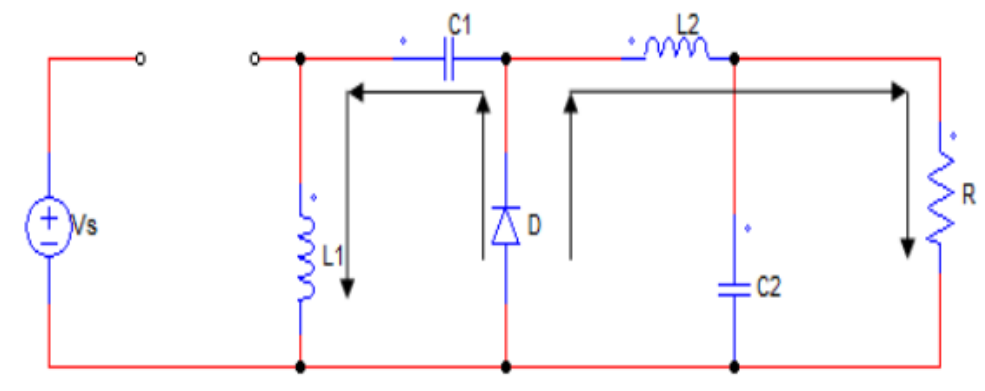

Figure 4 Equivalent circuit diagram during switch is OFF

\section{DESIGN OF L AND C PARAMETERS}

In loss less condition zeta converter act as CCM with given specific duty cycle is given as,

$$
D=\frac{V o}{V i+V o}
$$

[6]For two switching modes of operations KVL is applied and assuming $30 \%$ of ripple content current in the inductor with respect to input current $\left(\mathrm{I}_{\mathrm{in}}\right)$. The inductor values can be calculated with assumption that magnetically coupled with inductors are used with same content of ripple current for two both inductors $\left(\mathrm{L}_{1} \& \mathrm{~L}_{2}\right)$ by the equation given below,

$$
L 1=L 2=\frac{D V i n}{F * \Delta I}
$$

For both the switching modes KCL can be apply, the capacitor values can be calculated. Assuming ripple voltage of capacitor is 0.02 times the output voltage[3]. Thus equation for capacitors are given as,

$$
\begin{gathered}
C 1=\frac{D V o}{F * R * \Delta V} \\
C 2=\frac{D V i n}{8 * F^{2} * L 2 * \Delta V}
\end{gathered}
$$


Sujo Oommen, Adithya Ballaji, Burri Ankaiah, Ananda M H

Table 1 Design Specification of Zeta Converter

\begin{tabular}{|c|c|}
\hline Parameters & $\begin{array}{c}\text { Calculated } \\
\text { Values }\end{array}$ \\
\hline Vin & $100 \mathrm{~V}$ \\
\hline Vo & $\begin{array}{c}230 \mathrm{~V} \text { (Boost) } \& \\
42 \text { V(Buck }\end{array}$ \\
\hline D & $\begin{array}{c}70 \% \text { (Boost) } \\
30 \% \text { (Buck) }\end{array}$ \\
\hline F & $10 \mathrm{kHz}$ \\
\hline R & $40 \Omega$ \\
\hline L1 & $25 \mathrm{mH}$ \\
\hline L2 & $25 \mathrm{mH}$ \\
\hline C1 & $4 * 10^{4} \mathrm{~F}$ \\
\hline C2 & $7.6 * 10^{4} \mathrm{~F}$ \\
\hline
\end{tabular}

\section{SIMULATION \& RESULTS}

Simulation circuit for Zeta converter is carried out with an input voltage of $100 \mathrm{~V}$ to boost up to $230 \mathrm{~V}$ and step-down (buck) to $42 \mathrm{~V}$ with a duty cycle of $70 \%$ and $30 \%$ respectively. Output voltage to operate as buck and boost mode by changing the duty cycle of gate pulse to the MOSFET switch.

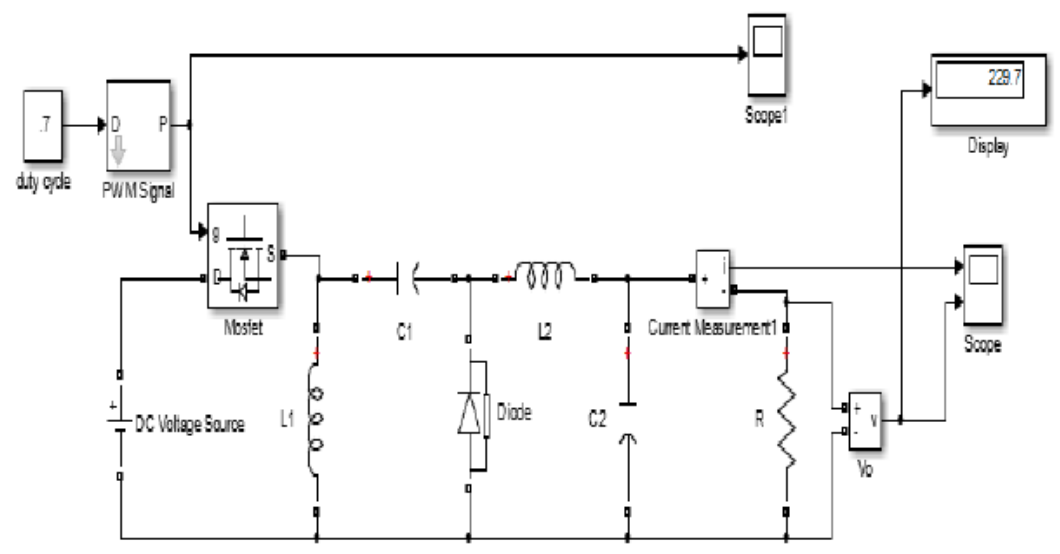

Figure 5 Simulation of ZETA converter for Boost Mode.

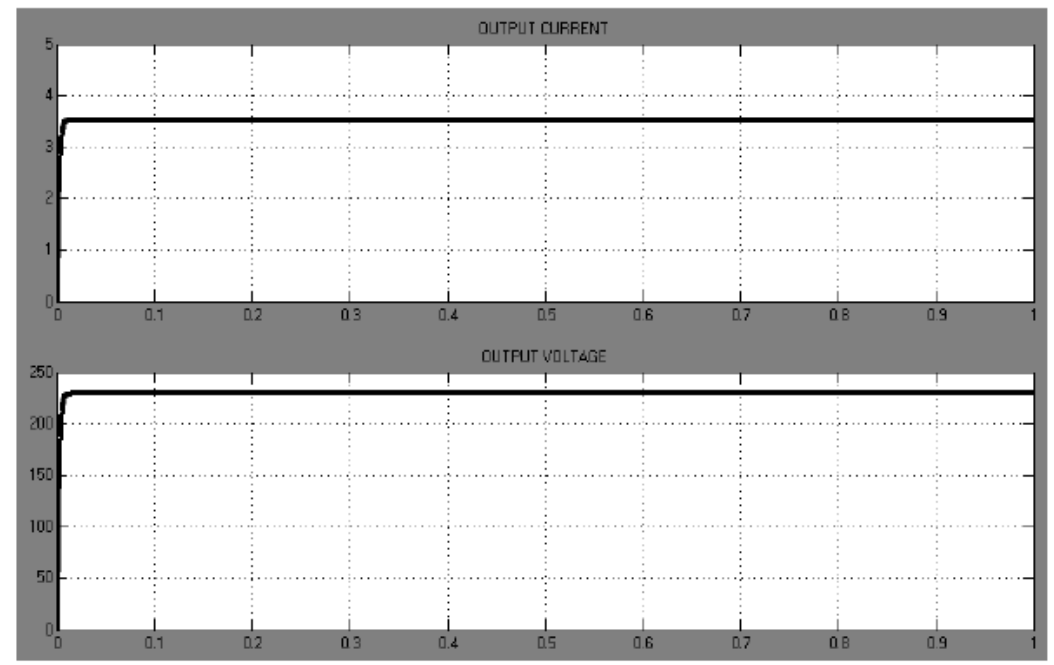

Figure 6 Output Voltage \& Current waveforms of ZETA converter for Boost Mode. 


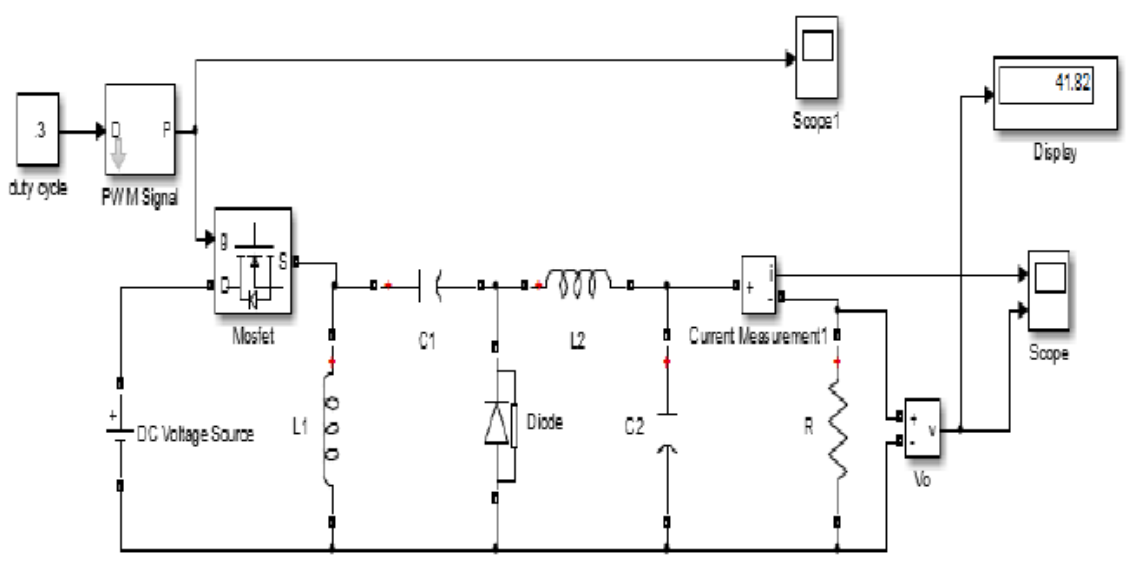

Figure 7 Simulation of ZETA converter for Buck Mode.

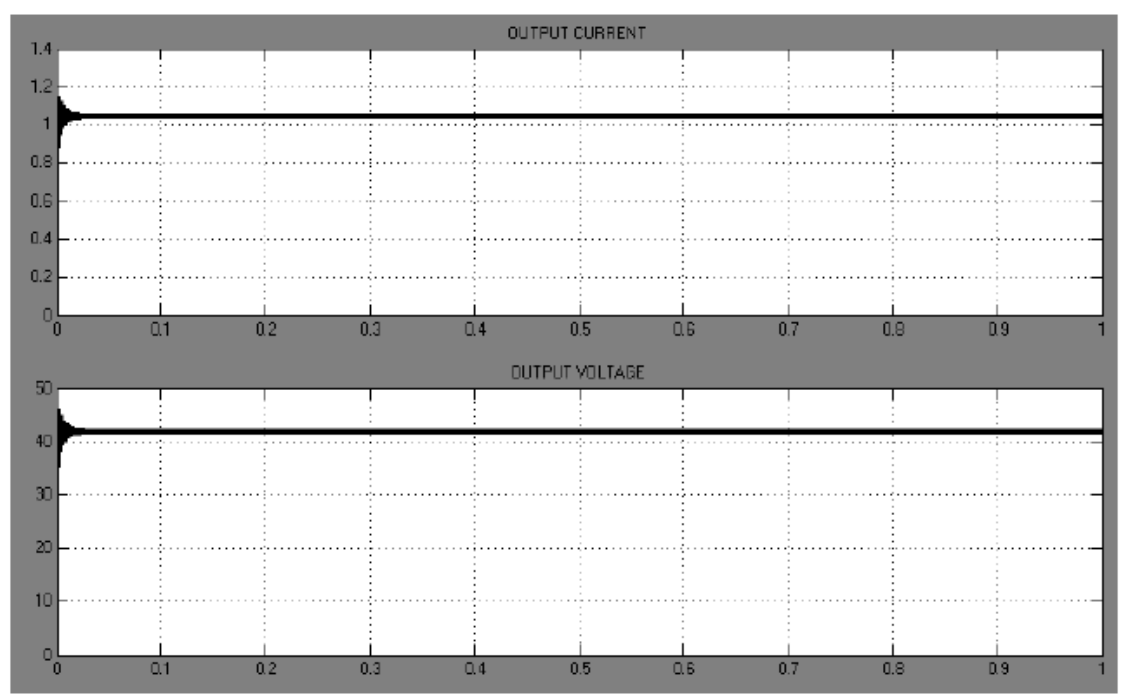

Figure 8 Output Voltage \& Current waveforms of ZETA converter for Buck Mode.

\section{CONCLUSIONS}

In this paper deals with the operation principle of Zeta converter and different operating modes with equivalent circuits. Zeta converter parameters are designed and simulation is carried from the obtained values. From simulation circuit, it is observed that with the same parameter design boost and buck converter operation is taking place by changing the duty cycle of $70 \%$ and $30 \%$ respectively. Simulation is Output voltage obtained from both operation having less ripple and reduced settling time. This converter overcomes the drawbacks of other converters, providing lower output voltage ripple and better compensation.

\section{REFERENCES}

[1] Jitty Abraham and K. Vasanth "Design and Simulation of Pulse Width Modulation Zeta converter with Power Factor Correction," International Journel of Advanced Trends in Computer Science and Engineering, vol. 2, No.2, pp. 232-238, Feb 2013.

[2] H. Parthsarathy, L. Udayakumar, G. Balasubramanian, " Modeling and simulation of PV module and zeta converter", International Conference on Circuit, Power \& Computing Technologies [ICCPCT], 2016 
[3] Jeff Falin, "Designing DC/DC converters based on ZETA topology," in Analog Application Journal Texas Instruments incorporated, 2010, pp. 16-21.

[4] N. Sowmya Smitha Raj, B. Urmila, "PV fed Zeta converter," International Journal of Engineering Research and Applications (IJERA) Vol. 3 Issue 4, Jul- Aug 2013, pp 2692- 2696.

[5] Ali H Ahmed, Nashwan Saleh Sultan, "Design and Implementation of controlled Zeta Converter Power Supply," American Journal of electrical \& Electronics Engineering (AJEEE), June 2014, Vol. 2, No.3, pp $121-128$.

[6] P. Ramesh Babu, S Ram Prasath, R Kiruthika, "Simulation and Performance Analysis of CCM Zeta Converter with PID controller", International Conference on Circuit, Power \& Computing Techologies[ICCPCT] Sept 2015

[7] J.S. Nancy Mary and Dr. K. Mala, Comparative study of ZETA and Single Stage High Voltage Gain DC-DC Converters, International Journal of Electrical Engineering \& Technology, 10(3), 2019, pp. 45-55

[8] Herawati Yusuf, The Influence of Air Gaps at 0.4 Duty Cycle on Magnetic Core Type 'E' to Increase the Efficiency of Cuk Converter, International Journal of Electrical Engineering and Technology (IJEET), Volume 4, Issue 2, March - April (2013), pp. 71-80. 